\title{
New Treatment for Regular Astigmatism Using Physical Exercises
}

\author{
Mundher Sameen Shuker \\ Assist Prof., Department of Optics Technology, College of Health and Medical Technology, Middle Technical \\ University, 10047 Bab Al Muadham, Baghdad, Iraq
}

\begin{abstract}
Introduction: Regular Astigmatism is one of the most common problems for the eye; it makes a patient unable to see things clearly. Therefore, the aim of the study estimates the incidence of regular astigmatism among age group (10-32) years by using physical exerciser in the college of health and medical technology. We perform therapeutic exercises in an applied scientific way to activate the towed eye muscles by the pulled during treatment sessions to get rid of regular astigmatism and improve vision without the use of glasses or surgery to patients.
\end{abstract}

Materials and Method: The method used in this study was a cross-sectional analysis of 100 cases (51 males) (49 females) with different types of astigmatism through physical exercise. The data analysed using the SPSS package program.

Results: We found the compound astigmatism (58\%) is higher than simple astigmatism (33\%), as well as the compound astigmatism is higher than mixed astigmatism (13\%). Also, we found to improve in (90\%) patients treatment for continuous exercise as requested by the therapist.

Conclusion: This study that most patients of Astigmatism were compound and improvement in $90 \%$ of cases treatment by physical exercise and did not need to use any glasses to read during the examination and get 'Visual Acuity' VA=6/6.

Keywords: Regular Astigmatism, Physical Exercises, New Treatment, Visual Acuity, Astigmatism Treatment.

\section{Introduction}

Astigmatism, considered to be one of a group of eye defects with certain sights, including myopia and hyperopia, known as Refractive Errors (R.E) ${ }^{(\mathbf{1})}$. This is also the concept of the inability of the cornea to focus the image on the retina; the effect is a blurred picture of the patient ${ }^{(2)}$. As they influence light refraction in the eyes, this creates a change in the way light beam focused in the eye, it simply means that the shape of your cornea is different ${ }^{(\mathbf{3})}$. Many symptoms may include eyestrain, headache, and night driving problems ${ }^{(\mathbf{4})}$. The stigmatism has many classifications, but there are two types of astigmatism, which are determined by the shape of the cornea: Irregular Astigmatism, and Regular Astigmatism $^{(5,6)}$. The two terms are defined:

Irregular Astigmatism is a kind of astigmatism that arises from the disruption of light rays caused by a cornea lens disorder ${ }^{(7)}$. Interruption is usually caused by illness or injury in one of these areas of the eye, resulting in surface irregularity and, consequently, distortion of the light rays that reaching the eye ${ }^{(7)}$. This type of astigmatism is only treated with surgical procedures or special type of contact lenses and will not be emphasized in this research.

Regular Astigmatism also, there is a type of astigmatism in different areas of the eye ${ }^{(7)}$, while light is not focused on the centre of the retina in normal conditions if the stabilizing beam is called near-sightedness or hyperopia in the retina in front of the eye ${ }^{(\mathbf{8})}$. There is one trend in all cases of regular astigmatism where the lines are very far and one in the right corners of this where conventional lenses (lenses, contact lenses, and surgery) tend to be more confusing and accurate. But today we 
correct the curative exercises of weak eye muscles in a different way from the previous one, and it is called muscle stimulation ${ }^{(9)}$. This type of astigmatism has three classes (simple astigmatism, complex astigmatism, and mixed astigmatism), and these types are known as:

A -Simple Astigmatism; is the one area of the eye is regular while the other is either myopia or hyperopia; therefore, when two or perpendicular lines have been seen, the line representing myopia or hyperopia is out of focus and blurred while the other line is clearly focused (10). The simple type of astigmatism is corrected by means of cylindrical lenses that guide the out of focus beam of the eye according to the power required ${ }^{(7,10)}$.

A- Compound Astigmatism Two primary meridians are described (Myopia, or Hyperopia). 1- Composite Astigmatism of Myopia, a beam in all meridians in front of the eye comes to a concentration. 2Hybrid astigmatism with hyperopia, a pulse in both meridians is focussed in the retina ${ }^{(11)}$.

B- Mixed Astigmatism; one of the definitions of the meridian is myopia, while the other is hyperopia. In combination and mixed types, the ring is attached to the spherical lenses to create a clear image ${ }^{(11,12)}$.

The incidence of astigmatism usually refers to the overall population of people who treat it at any given time ${ }^{(13)}$. The incidence of high levels of astigmatism among Americans is greater (1D)*. That key fundamental causes have postulated is inherited.

In $1995,11 \%$ of schoolchildren in Taiwan had astigmatism (1D-2D) and 1.3\% (3D). While in 2000 it was $13 \%$ had astigmatism (1D-2D), and $1.8 \%$ (3D). The incidence of myopic astigmatism increased with age, but the comparison is a reduction in the rate of hyperopic and mixed astigmatism with age 17 years ${ }^{(14)}$. Most of the children had astigmatism were from East Asia 17.2\%, the Middle East 4.9\%, and South America 0.9\%(15).

$*(\mathrm{D}=$ Dioptre $)$

Astigmatism treatment at first, if the degree of astigmatism is small, and there are no other refractive problems, such as Myopia or Hyperopia, corrective lenses may not be required ${ }^{(11)}$. While, if the degree of astigmatism causes visual loss or pain, it will prescribe prescription lenses ${ }^{(16)}$. However, there are very effective alternatives, such as eye robins, which allow a clear vision of contact lenses or glasses to be restored naturally ${ }^{(17)}$. There are three common types of Astigmatism treatment:
1. Eye-glasses: a method of correction for people with astigmatism. In order to account for astigmatism, it must contain a special cylindrical lens prescription in only specific lens meridians; this provides additional lens power ${ }^{(\mathbf{1 8})}$. A single vision lens is a clear vision at all distances, but when the patient is 40 years of age, it is considered presbyopia ${ }^{(\mathbf{1 7}, 19)}$.

2. Contact lens (C.L): is a better vision than eyeglasses; it can provide a clearer vision and a wider FOV because C.L is worn directly on the eyes, but regular cleaning and care are needed to protect and safety of the eyes ${ }^{(20)}$.

3. Surgery: it has two method of astigmatism treatment by surgery. First, Implantation of contact lens: Recent attempts to surgically implant contact lenses for correction of regular astigmatism have also been found effective ${ }^{(21)}$. Second, refractive surgery (LASIK): improves vision and removes the need for eyeglasses and contact lenses ${ }^{(22,23)}$. Your eye surgeon uses a laser beam to reshape corneal curves to correct astigmatism before surgery ${ }^{(\mathbf{2 3}, 24)}$; doctors will assess you and determine whether or not you are a candidate for LASIK astigmatism ${ }^{(25,26)}$.

\section{Materials and Method}

Materials: The research group consists of 100 patients with Regular Astigmatism (51 Male, 49 female). All patients were exposed to regular physical activity, astigmatism therapy, and attending the clinical advisory in the Medical and Health Technology Collage. It was the criteria for selecting patients with astigmatism and determines the level of natural astigmatism at the age of 10-30 years. Then all information was done by means of a direct questioner, including (age, gender, family history, and glass wearing).

Method: The method will use four-step procedures for regular astigmatism. Initially, the use of the (automatic refractormeter) for an automatic tool automatically measures the power of eye focus. Second (visual acuity); This test was used to measure the VA, requesting the patient to read messages using the Snellen chart or cubes. Third (retina range), the patient adjusts and looks directly at the Snellen chart for about 6 meters, the doctor holds the instrument for about 0.5 to 1 or 1.5 meters, and light from the device directs the patient's eye to see the type and measure the degree of regular astigmatism for each individual eye. Finally, conducting therapeutic exercises in an integrated scientific way to stimulate the muscles 
of the eye without closing the healthy eye after placing the cornea in the centre of the eye and using a principle pinholl and then the eyes are drilled without movement for a period of 15 minutes depending on the experience of the therapist until a straight movement in addition to conducting training at home before Parents need to maintain the amount of improvement that they got in each session of treatment sessions to get rid of regular astigmatism. Initially, using glasses for three sessions occurs to determine the extent of improvement exercises and then the continuous exercise without glasses.

\section{Results}

In the beginning, it is noted that most types of treatment use glasses and in the case of leaving or not wearing the glasses are returned to their old position. But in this method, what has been done to the patient by means of therapeutic exercises to stimulate the eye muscles and to conduct an optician test without affecting the eye and the possibility of getting $\mathrm{VA}=6 / 6$ and removing the glasses, the results show all that.

Table (1) shows the samples were 100 patients, split into 51\% male and $49 \%$ female. Higher percentages at age groups $10-15$ years were ratio formed $51 \%$, while the proportion was $11 \%$ for people $22-27$ years of age. This means that the highest percentage is children, so the patient's family needs to help the patient conduct therapy exercises.
Table (1): Distribution of cases of regular astigmatism according to age groups (years) and gender.

\begin{tabular}{|l|c|c|c|c|c|c|}
\hline \multirow{2}{*}{$\begin{array}{l}\text { Age Groups } \\
\text { (Years) }\end{array}$} & \multicolumn{2}{|c|}{ Male } & \multicolumn{2}{c|}{ Female } & \multicolumn{2}{c|}{ Total } \\
\cline { 2 - 7 } & $\mathbf{N}$ & $\%$ & $\mathbf{N}$ & $\%$ & $\mathbf{N}$ & $\%$ \\
\hline $15-10$ & 29 & $29 \%$ & 22 & $22 \%$ & 51 & $51 \%$ \\
\hline $21-16$ & 06 & $6 \%$ & 19 & $19 \%$ & 25 & $25 \%$ \\
\hline $27-22$ & 06 & $6 \%$ & 05 & $5 \%$ & 11 & $11 \%$ \\
\hline Up to 32 & 10 & $10 \%$ & 03 & $3 \%$ & 13 & $13 \%$ \\
\hline
\end{tabular}

It is evident that the aetiology of the types of daily astigmatism in 100 patients is the majority of smart devices such as (x-box, play station, and mobile) where the proportion $67 \%$ of the total causes is considered to be the most common among other causal types. While, it was found $25 \%$ because of continuous reading with neglect of wearing glasses and lack of therapeutic exercises. We also found that compound astigmatism has been aggravated in $58 \%$ of cases. Table (2) show the distribution of all 100 patients according to causes by types of regular astigmatism.Also, It is evident from Table (3) that the case with compound Astigmatism were $58 \%$ regular the distribution of astigmatism according to age groups (years), which found that 20 cases were having compound astigmatism \& were at age group 1621 years.

Table (2): Distribution of samples according to causes by types of regular astigmatism.

\begin{tabular}{|l|c|c|c|c|}
\hline \multirow{2}{*}{ Types of Regular Astigmatism } & \multicolumn{3}{|c|}{ Causes } & \multirow{2}{*}{ Others } \\
\cline { 2 - 5 } & Smart Devices & Continuous Reading & 3 & 33 \\
\hline Simple Astigmatism & 22 & 8 & 4 & 58 \\
\hline Compound Astigmatism & 40 & 14 & 1 & 09 \\
\hline Mix Astigmatism & 05 & 03 & $\mathbf{8}$ & $\mathbf{1 0 0}$ \\
\hline Total & $\mathbf{6 7}$ & $\mathbf{2 5}$ & & \\
\hline
\end{tabular}

Table (3): Distribution of cases of regular astigmatism by age (year) and type of regular astigmatism.

\begin{tabular}{|l|c|c|c|c|}
\hline \multirow{2}{*}{ Age Groups (Year) } & \multicolumn{3}{|c|}{ Type of regular astigmatism } & \multirow{2}{*}{ Total } \\
\cline { 2 - 5 } & Simple & Compound & Mixed & $28 \%$ \\
\hline $10-15$ & 10 & 15 & 3 & $39 \%$ \\
\hline $16-21$ & 15 & 20 & 4 & $20 \%$ \\
\hline $22-27$ & 5 & 13 & - & $13 \%$ \\
\hline Up to 32 & 3 & 10 & $\mathbf{9}$ & $\mathbf{1 0 0} \%$ \\
\hline Total & $\mathbf{3 3}$ & $\mathbf{5 8}$ & & \\
\hline
\end{tabular}


According to Visual acuity (VA) of patients with glasses, the highest rates of patient physical exercise therapy $94.8 \%$ found 55 cases out of 58 whose visual accuracy exceeds the compound form of regular astigmatism. In contrast, the lower rates of patient physical exercise therapy $44.4 \%$ in 4 cases out of 9 of their VA with glass reaches in mixed astigmatism. Table (4)show the distribution Visual Acuity (VA) of cases without glasses and form of Regular Astigmatism (simple, compound, and mixed) before and after treatment without glass.

Table (4): Distribution Visual Acuity (VA) of cases of Regular Astigmatism (R.A) before and after treatment without glass.

\begin{tabular}{|l|c|c|c|c|c|c|c|c|}
\hline \multirow{2}{*}{ Type of (R.A) VA } & \multicolumn{6}{|c|}{ Type of Regular Astigmatism (R.A) before and after treatment } & \multicolumn{2}{c|}{ Total } \\
\cline { 2 - 9 } & \multicolumn{2}{|c|}{ Simple } & \multicolumn{2}{c|}{ Compound } & \multicolumn{2}{c|}{ Mixed } & \multicolumn{2}{c|}{} \\
\cline { 2 - 9 } & Before & After & Before & After & Before & After & Before Treatment & After Treatment \\
\hline C.F- $6 / 60$ & 12 & 12 & 20 & 19 & 3 & 2 & 35 & 33 \\
\hline $6 / 36-6 / 24$ & 10 & 9 & 18 & 16 & 3 & 1 & 31 & 26 \\
\hline $6 / 18-6 / 12$ & 5 & 4 & 12 & 12 & 1 & 1 & 18 & 17 \\
\hline $6 / 9-6 / 6$ & 6 & 6 & 8 & 8 & 2 & -- & 16 & 14 \\
\hline Total & $\mathbf{3 3}$ & $\mathbf{3 1}$ & $\mathbf{5 8}$ & $\mathbf{5 5}$ & $\mathbf{9}$ & $\mathbf{4}$ & $\mathbf{1 0 0}$ & $\mathbf{9 0}$ \\
\hline
\end{tabular}

R.A= Regular Astigmatism, VA= Visual Acuity, $C . F=$ Count Figure

Table (5): Distribution of cases of regular astigmatism by groupage and family history.

\begin{tabular}{|c|c|c|c|c|c|c|}
\hline \multirow{3}{*}{ Family history Age } & \multicolumn{4}{|c|}{ Family history } & \multirow{2}{*}{\multicolumn{2}{|c|}{ Total }} \\
\hline & \multicolumn{2}{|c|}{ Positive } & \multicolumn{2}{|c|}{ Negative } & & \\
\hline & $\mathbf{N}$ & $\%$ & $\mathbf{N}$ & $\%$ & $\mathbf{N}$ & $\%$ \\
\hline $10-15$ & 15 & $37.5 \%$ & 25 & $41.5 \%$ & 40 & $40 \%$ \\
\hline $16-21$ & 12 & $30 \%$ & 20 & $33.5 \%$ & 32 & $32 \%$ \\
\hline $22-27$ & 7 & $17.5 \%$ & 10 & $16.5 \%$ & 17 & $17 \%$ \\
\hline Up to 32 & 6 & $15 \%$ & 5 & $8.4 \%$ & 11 & $11 \%$ \\
\hline Total & 40 & $40 \%$ & 60 & 60 & 100 & $100 \%$ \\
\hline
\end{tabular}

Table (5) shows that cases with a negative family history of astigmatism accounted for more than $60 \%$ of those without a negative family history, particularly those with a $41.5 \%$ negative family history age group of 10-15 years.

\section{Discussion}

The number of males is marginally higher than that of females for a retrospective study of medical data on 100 patients, the proportion of males is $51 \%$, while the ratio of females is $49 \%$. In this study, we found that $52 \%$ of patients have a complex type of normal astigmatism and that most patients have modified the way visual acuity(VA) is viewed from prescription glasses to physics therapy exercises. This is the ease of therapeutic exercises with the use of medicinal drugs and $90 \%$ of patients have been treated, most of them were the degree of vision produced $6 / 6$ without glasses.

It also found that the prevalence of astigmatism in patients between the ages of 10 and 15 due to the excessive use of electronic devices (smart devices) and their inability to wear glasses when continuous reading is caused by a higher prevalence of $16 \%$ between the ages of 16 and 21 . For this report, the number of patients who use smart devices are $67 \%$.According to a study carried out in the United States, we found similar results in which compound astigmatism is more prevalent among students than simple and mixed astigmatism. In addition, Family history is a significant risk factor in children with regular astigmatism. 
Clinical initiatives and identification of method of treatment have shown how patient outcomes can be improved, that is, by recognizing and moving weak eye muscles and finding the test. During exercises 1-6 sessions, the patient turns the eye in all directions and forces it forward to minimize the eye muscle pressure by about 15 minutes to strengthen the weak eye. Therefore, both patients were treated and strengthened in the degree of concern of each session with therapeutic exercises and did not need to use any glasses to read during the test and to achieve " visual acuity ' $\mathrm{VA}=6 / 6$.

\section{Conclusion}

It was recommended that all patients should be tested for their visual acuity and that all cases of astigmatism (regular astigmatism) should be treated with glasses at first and checked every six months to see the difference in the degree of astigmatism that, if any, or any complications in the eye due to misuse of smart devices (It is necessary to use MC-lenses to prevent harmful radiation from smart devices). It must to treat by Physical exercises and at least advised the patient wearing glasses and conduct exercises according to instructions the therapist. After the end of this study are advised to adhere to therapeutic exercises to get rid form correct regular astigmatism. Upon completion of this research are advised to adhere to therapeutic exercises to get rid form regular astigmatism.

Acknowledgments: The author would like to thank the patients who have kindly offered their time to take the information and confidence in the treatment method. The author would also like to thank the College of Health and Medical Technology, Middle Technical University, Baghdad, Iraq, for their moral support.

\section{Conflict of Interest: Non}

Source of Findings: Self-findings.

\section{Ethical Clearance: Non}

\section{References}

1. Andrew A. Dahl, MD, FACS. Astigmatism; 2012. https://www.emedicinehealth.com/astigmatism/ article_em.htm\#what_is_an_astigmatism

2. Gary Heiting, OD. What is astigmatism? 2018. https://www.allaboutvision.com/conditions/ astigmatism.htm

3. Read, Scott A; Collins, Michael J;Carney, Leo G.A review of astigmatism and its possible genesis. Clinical and Experimental Optometry; 2007.

4. Gilbert Smolin; Charies Stephen Foster; Dimitri T-Azar; Claes H.Dohlman.Smolin and Thofts the Cornea; Scientific Foundations and Clinical Practice; 2005.PP173.

5. Afsaneh Khetrapal, BSc Astigmatism TypesRegular and Irregular. News Medical Life Sciences; 2018.

6. Waddell K. Spherical refraction for general eye workers. J comma eye health 2000, 6-7.

7. Mohamed EL-Rifai. Text Book of Clinical Ophthalmic Optics. Egypt, 2007.

8. Carlo Cavallotti; Luciano Cerulli.Age - Related changes of the human eye. Springer Science \& Business Media; 2008.pp49.

9. Harvery, EM. Development and treatment of astigmatism. Optometry and vision science; official publication of the American Academy of optometry; 2009.

10. Boyd, Benjamin F. Modern Ophthalmology, The high lights. Panama; Jaypee Brothers Medical Pub; 2011. P.388.

11. Mozayan,E, Lee, astigmatism management. Current opinion in ophthalmology. 2014.

12. Kleinstein, R. N. Jones, LA; Hullett, S. Refractive Error and Ethnicity in Children; 2003.

13. Bourne, R; Dineen, BP;Ali, SM; Noorul Huq, DM; Johnson, GJ. Prevalence of refractive error in Bangladeshi adults; 2004.

14. Yung-Feng Shih. The Prevalence of Astigmatism in Taiwan Schoolchildren, Optometry and Vision Science; 02/2004.

15. Ostadimoghaddam $\mathrm{H}$, Fotouhi A, Hashemi $\mathrm{H}$, Yekta A. Heravian J, Re zvan F,et al. Prevalence of the astigmatism by age and gender in Mashhad, Iran: The Mashhad eye study . Clin Experiment Ophthalmic; 2011.

16. Andrew A. Dahl, MD, FACS. Astigmatism. Medicine Net; 2013.https://www.medicinenet.com/ astigmatism_overview/article.htm\#astigmatism_ facts

17. Gary L. Mancil, O.D., (Principal Author). Optometric Clinical Practice Guideline Care of the Patient with Presbyopia. American Optometric Associattion; 2011.

18. George Biddel Airy. On a peculiar Defect in the 
eye, and a mode of correcting it. Transactions of the Cambridge Philosophical Society; 28 October 2016.

19. Jack J. Kanski, MD, MS, FRCS, FRCOphth. Clinical ophthalmology: A Systematic Approach, Book, Clinical Ophthalmology;2006.

20. Grame Young, Anna Sulley, Chris Hunt. Prevalence of astigmatism in relation to soft contact lens fitting. Eye \& contact lens, 2011.

21. Rose Kivi, and Elizabeth Boskey, PhD Medically, MD on November, 2015.

22. Azar Dimitri T. Refractive surgery (2nd). Mosby Elsevier; 2007.
23. Munther. S SH.,Zina T.A, The biophysical efficacy of smart phoneson the eyes of children from $3=12$ years,Indian Journal of Forensic Medicine \& Toxicology.2020.

24. Sophie J. Bakri, M.D. Book: Mayo Clinic Guide to Better Vision. 2019. https://www.mayoclinic. org/tests-procedures/lasik-eye-surgery/about/pac20384774

25. PK Mukherjee MS Ophth. Manual of optics \& Refraction, Refractive Surgeries; 2015 pp212-232.

26. Ming Wang, $\mathrm{MD}, \mathrm{PhD}$. Irregular Astigmatism Diagnosis and Treatment, Book; 2008. 